\title{
DOES TREATMENT WITH N-BUTYL CYANOACRYLATE EMBOLIZATION PROTECT AGAINST HEMORRHAGE IN CEREBRAL ARTERIOVENOUS MALFORMATIONS?
}

\author{
Eduardo Floriani Raupp ${ }^{1}$, Jefferson Fernandes ${ }^{2}$
}

\begin{abstract}
Objective: To assess the role of this procedure to prevent hemorrhage in cerebral arteriovenous malformations (CAVM). Method: Between 1992 and 2000, we studied 104 patients submitted to embolization as the main treatment. Patients were followed until hemorrhage or death. Results: Follow-up ranged from 1.6 months to 8 years. The most frequent presentations were hemorrhage $(50 \%)$ and seizures $(38 \%)$. In addition, $40 \%$ were small $(<30 \mathrm{~mm}) ; 56 \%$ were medium ( $30-60 \mathrm{~mm}$ ). Obliteration was $\leq 1 / 3$ in $11 \%$ of the cases; from $1 / 3$ to $\leq 2 / 3$ in $49 \%$; $>2 / 3$ in $36 \%$; complete in $5 \%$. The risk of death was $1 \% / y$ ear, and of bleeding, 5.4\%/year. Presentation with hemorrhage and low obliteration rate were the main factors associated with hemorrhage. Conclusion: CAVM embolization provides limited protection against hemorrhage with obliteration rates below $2 / 3$. Presentation with hemorrhage is the main factor for predicting hemorrhage.
\end{abstract}

KEY WORDS: therapeutic embolization, intracranial hemorrhage, bucrylate, intracranial arteriovenous malformation.

\begin{abstract}
Embolização com $\mathbf{N}$-butil cianoacrilato confere proteção contra hemorragia em malformações arteriovenosas cerebrais?

RESUMO - Objetivo: Avaliar o papel deste procedimento na prevenção de hemorragia em casos de malformação arteriovenosa (MAV) cerebrais. Método: Entre 1992 e 2000, estudamos 104 pacientes submetidos a embolização como tratamento principal. Os pacientes foram seguidos até a ocorrência de hemorragia ou morte. Resultados: 0 período de seguimento variou de 1,6 mês a 8 anos. As apresentações mais freqüentes foram hemorragia $(50 \%)$ e convulsões ( $38 \%$ ). Além disso, $40 \%$ das lesões eram pequenas ( $<30 \mathrm{~mm}$ ); $56 \%$ eram médias (30-60 mm). 0 grau de obliteração foi $\leq 1 / 3$ em $11 \%$ dos casos; $1 / 3$ a $\leq 2 / 3$ em $49 \%$; $>2 / 3$ em $36 \%$; completa em $5 \%$. O risco de morte foi 1\%/ano, e de sangramento, 5,4\%/ano. Apresentação com hemorragia e baixo grau de obliteração foram os principais fatores associados com hemorragia. Conclusão: A embolização em MAVs cerebrais confere proteção limitada contra hemorragia, com graus de obliteração abaixo de 2/3. Apresentação com hemorragia é o principal fator preditivo de hemorragia.
\end{abstract}

PALAVRAS-CHAVE: embolização terapêutica, hemorragia intracraniana, bucrilato, malformação arteriovenosa intracraniana.

Cerebral arteriovenous malformations (CAVM) are characterized by a plexus of histologically undifferentiated vessels in which veins and arteries are directly connected without the usual intervening capillary network. These congenital lesions usually affect otherwise healthy individuals, and are most often diagnosed by the age of 40 years. The usual symptoms are hemorrhage (about $50 \%$ of the cases), seizures $(30 \%)$, headaches $(20 \%)$, progressive neurological deficit ( $5 \%)$, and other less common presentations $(5 \%)^{1}$. The risk of hemorrhage varies from 2 to $4 \%$ per year, and may reach $18 \%$ after a first bleeding episode ${ }^{1-4}$. Hemorrhage is usually associated with 10 to $15 \%$ morbidity in CAVM, and this rate increases after each recurrence ${ }^{4-6}$. The mortality rate in patients with untreated CAVM has been estimated at $1 \%$ per year ${ }^{7}$.

The main goal of treatment in CAVM is the prevention of hemorrhage, although it is also indicated in the presence of seizures and progressive neurological deficit ${ }^{8,9}$. The factors that are known to predispose to the occurrence of hemorrhage are smallsized lesions, deep or posterior fossa location, deep venous drainage, venous stenosis, elevated per-

\footnotetext{
'Pontifícia Universidade Católica do Rio Grande do Sul (PUCRS), Porto Alegre RS, Brazil: 'Interventional Neuroradiology Service, Hospital São Lucas PUCRS; ${ }^{2}$ Professor of Neurology, School of Medicine, PUCRS. Eduardo Raupp was the recipient of a scholarship awarded by Conselho de Aperfeiçoamento de Pessoal de Ensino Superior (CAPES).
}

Received 20 February 2004, received in final form 21 July 2004. Accepted 18 September 2004.

Dr. Eduardo F. Raupp - Rua André Puente 200/301 - 90035-150 Porto Alegre RS - Brasil. E-mail: eraupp@uol.com.br 
fusion pressure, and presence of aneurysms $\mathrm{s}^{2,3,10-13}$. Some investigators claim that presentation with seizures may be a protective factor against hemorrhage in untreated cAVMs. 1,3,14 Hemorrhage can only be prevented by total obliteration or excision of the lesion, since residual pathologic vessels may cause bleeding ${ }^{8,15}$. Several studies have also reported that embolization in CAVM may be useful in the management of patients presenting hard-to-control seizures, progressive neurological deficit, and headaches, and to improve cerebral perfusion ${ }^{8,9,16}$. In addition, embolization has been thought to be useful in the elimination of aneurysms, which are

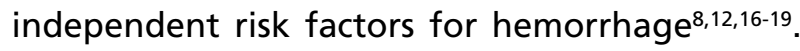
However, there are no conclusive data concerning the benefits of this procedure. In addition, since embolization is usually performed as a preoperative measure ${ }^{20}$, there is a dearth of data concerning the effects of embolization alone on prevention of hemorrhage in CAVM.

Therefore, the objective of the present paper was to assess the role of embolization to prevent hemorrhage and the association of this procedure with several known potential risk factors in a population of patients submitted to embolization alone, or submitted to surgery more than two months after the performance of embolization.

\section{METHOD}

The present study was carried out from January 1992 to June 2000. We studied a cohort of 104 patients who a) were submitted to embolization only because this was the indicated treatment; b) had an indication for embolization followed by surgery or radiosurgery but abandoned this initial protocol and were submitted to embolization only; or c) underwent surgery more than two months after embolization. All presented plexiform pial CAVM. No control group was established for ethical reasons (it would be unethical not to treat patients at risk for hemorrhage). Patients who had been previously submitted to surgery or radiation therapy were excluded. The study was approved by the appropriate Bioethics Research Committees. All patients provided written informed consent.

Data were collected for each patient starting with the first embolization session until the occurrence of either hemorrhage or death or until their last clinical evaluation. Patients who did not present either outcome until the last clinical evaluation were censored from the analysis. Demographic data (sex and age) and information about clinical presentation were collected during anamnesis or from the patient's medical chart. We also collected data about CAVM topography, size, angiographic aspects (venous drainage and association with aneurysms) and percentage of obliteration after the last embolization session.

All embolizations were carried by the same professional (E.F.R.) and employed catheters (mostly flow-directed) with or without a microguidewire system. For all procedures, a mixture of NBCA (Histoacryl B, Braun, Melsugen AG, Germany) and lipiodol (Lipiodol UF, Guerget, France) without tantalum was used. Until 1995, pedicular injection and the full-column injection technique were used. After that, intranidal injection with induced hypotension was used whenever possible (considering the whole study period, pedicular injection was used in 29 patients, intranidal injection in 62, and in 13 patients both procedures were used).

Since the assessment of CAVM obliteration is subjective (based on visual inspection), we divided each lesion into three-thirds, and patients were classified into four categories according to the rate of obliteration achieved: $\leq 1 / 3 ;>1 / 3$ to $\leq 2 / 3$; $>2 / 3$; or complete.

Statistical analysis - Cumulative incidence, density of incidence and their confidence intervals were calculated for the occurrence of death or hemorrhage. In addition, Kaplan-Meier curves were plotted, and measures of association between the outcomes of interest and potential risk factors were calculated, as well as relative risk (RR) and confidence intervals. The chi-square test was used to determine the significance of results. Cox proportional hazards regression modeling was used to evaluate the effect of risk factors selected on the bivariate analysis on the occurrence of hemorrhage. The significance leveIs were $\alpha=0.05$ for the bivariate analysis and $\alpha=0.10$ for the multivariate analysis. Data were processed and analyzed using the SPSS 9.0 software.

\section{RESULTS}

Of the 104 patients assessed, 57\% were male, and age (mean \pm standard deviation) was $30 \pm 13$ years. The most common clinical presentation was hemorrhage $(50 \%)$, followed by seizure $(38 \%)$, headache $(9 \%)$, and other (3\%). Lesion topography was frontal in $29 \%$ of cases, parietal in $23 \%$, temporal in $19 \%$, deep in $17 \%$, infratentorial in $7 \%$, and occipital in $5 \%$. In relation to size, most lesions were small $(<30 \mathrm{~mm})$ and medium $(30-60 \mathrm{~mm})$, with $40 \%$ and $56 \%$, respectively.

Follow-up ranged from 1.6 months to 8 years. In our cohort of 104 patients, 18 presented hemorrhage following embolization and four died. This means a density incidence of 1.1 and a cumulative incidence of 3.8 per 100 patients for death $(95 \%$ $\mathrm{Cl}=1.1-9.6$; patients at risk/year $=367.61$ ); for bleeding, the density incidence was 5.4 and the cumulative incidence was 17.3 per 100 patients $(95 \% \mathrm{Cl}$ $=10.6-26.0$; patients at risk/year $=333.59)$. When 


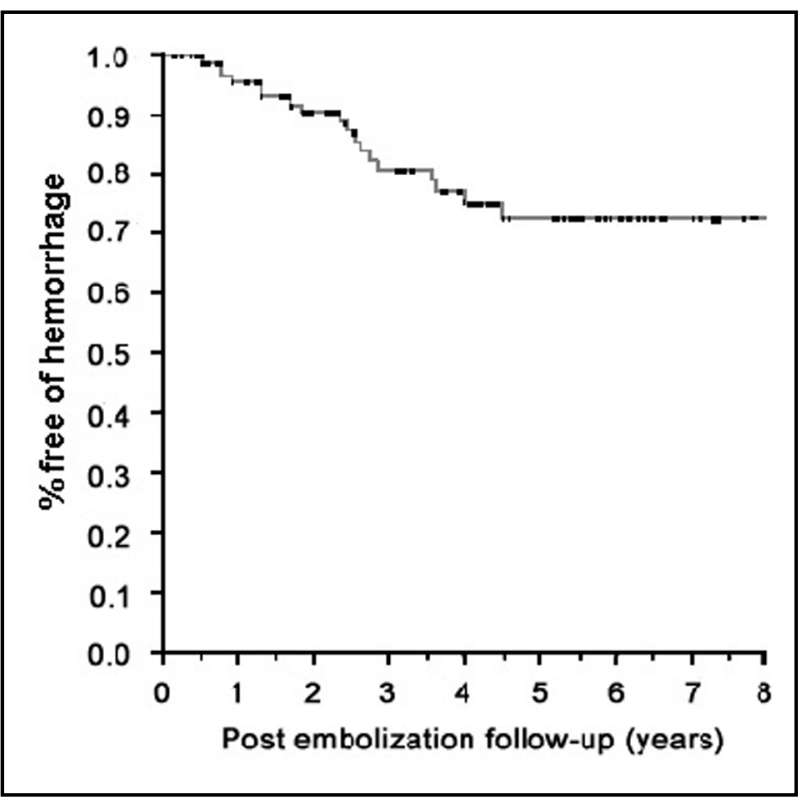

Fig 1. Occurrence of hemorrhage following embolization in cAVM patients.

considering only the 98 patients who underwent partial embolization, the density incidence was 5.6 (non significant).

Twenty patients presented 23 aneurysms; 16 of these aneurysms $(70 \%)$ were intranidal. The rate of obliteration achieved with embolization was $\leq 1 / 3$ in $11 \%$ of the cases; from $1 / 3$ to $\leq 2 / 3$ in $49 \%$; $>2 / 3$ in $36 \%$; and complete in $5 \%$. During the course of treatment with embolization, there were 18 cases $(22.5 \%$ ) of early complications (up to 72 hours after the procedure), distributed as follows: three cases $(17 \%)$ of hemorrhagic complications that did not require surgery; 11 cases (61\%) of ischemic com- plications; and four ( $22 \%$ ) cases of seizures. Most of these complications were transient, but in three cases they resulted in permanent neurological deficit.

Figure 1 shows that the rate of occurrence of hemorrhagic events was relatively constant along the first four years. From that point on, the hemorrhage rate decreased significantly.

Table 1 shows that the factors that were most significantly associated with post-embolization in the bivariate analysis were deep topography, medium or large CAVMs, presentation with hemorrhage, presence of aneurysm, and low obliteration rate. Figure 2 shows the association between death or hemorrhage and presentation with hemorrhage, topography and obliteration rate.

The Cox proportional hazards regression model (Table 2) confirmed the results of the bivariate analysis concerning low obliteration rate and presentation with hemorrhage, which remained as high risk factors. However, the relative risk of deep topography was significantly reduced, from high to moderate. Moreover, the presence of aneurysm (moderate relative risk on bivariate analysis) had its

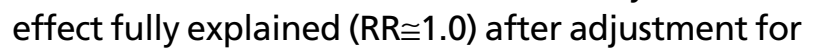
the variables included in the multivariate analysis.

\section{DISCUSSION}

The prevention of hemorrhage is the main goal of treating cAVMs. Currently, cAVMs are usually treated with embolization followed by surgery or complementary obliteration with radiosurgery ${ }^{8}$. According to Spetzler and Martin, preoperative embolization of small and superficial cAVMs located in surgically accessible noneloquent locations brings little benefit ${ }^{21}$. However, it is important to note that
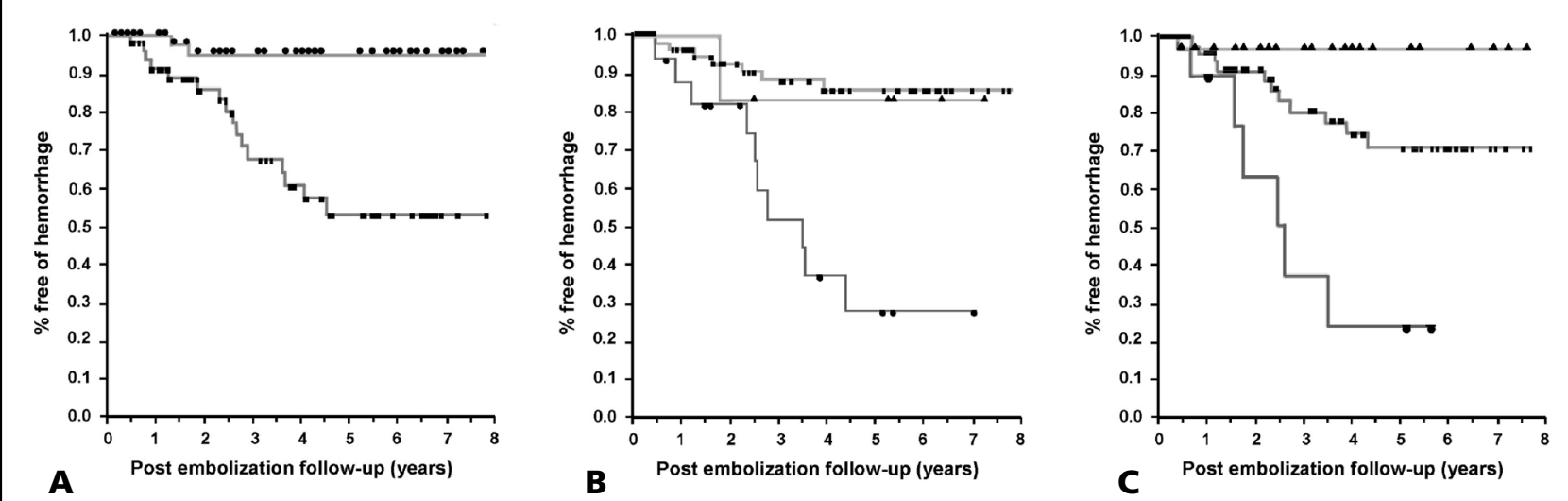

Fig 2. Occurrence of hemorrhage following embolization in (AVM patients according to A) presentation with (squares) or without (circles) hemorrhage; B) convexity (squares), infratentorial (triangles), or deep (circles) topography; and C) obliteration rate $\geq 2 / 3$ (triangles); $>1.3$ or $<2 / 3$ (squares); or $\leq 1 / 3$ (circles). 
Table 1. Bivariate analysis of the correlation between hemorrhage after embolization in cAVM patients and several variables

\begin{tabular}{|c|c|c|c|c|c|c|c|}
\hline Variable & $\mathrm{N}$ & $\mathrm{F}$ & $\begin{array}{l}\text { Patients at } \\
\text { risk/year }\end{array}$ & Di & $\mathrm{RR}$ & $95 \% \mathrm{Cl}$ & $p$ \\
\hline \multicolumn{8}{|l|}{ Topography } \\
\hline Convexity & 79 & 7 & 251.53 & 2.78 & 1.00 & _ & - \\
\hline Deep & 18 & 10 & 52.64 & 19.00 & 6.83 & 2.60 to 17.93 & $<0.001$ \\
\hline Infratentorial & 7 & 1 & 29.42 & 3.40 & 1.22 & 0.15 to 9.93 & 0.587 \\
\hline \multicolumn{8}{|l|}{ Size } \\
\hline Small & 41 & 2 & 142.52 & 1.40 & 1.00 & - & - \\
\hline Medium & 58 & 14 & 171.26 & 8.17 & 5.83 & 1.32 to 25.63 & 0.010 \\
\hline Large & 5 & 2 & 19.81 & 10.10 & 7.19 & 1.01 to 51.08 & 0.075 \\
\hline \multicolumn{8}{|l|}{$\begin{array}{l}\text { Presentation with } \\
\text { hemorrhage }\end{array}$} \\
\hline Yes & 52 & 16 & 155.52 & 10.29 & 9.16 & 2.11 to 39.84 & $<0.001$ \\
\hline No* & 52 & 2 & 178.07 & 1.12 & 1.00 & - & - \\
\hline \multicolumn{8}{|l|}{ Aneurysm } \\
\hline Yes & 20 & 7 & 60.61 & 11.55 & 2.87 & 1.11 to 7.39 & 0.032 \\
\hline No* & 84 & 11 & 272.99 & 4.03 & 1.00 & _- & - \\
\hline \multicolumn{8}{|l|}{ Obliteration rate } \\
\hline$\leq 1 / 3^{*}$ & 11 & 6 & 27.0 & 22.22 & 1.00 & - & - \\
\hline$>1 / 3$ to $\leq 2 / 3$ & 51 & 11 & 199.32 & 5.52 & 0.25 & 0.09 to 0.67 & 0.011 \\
\hline$>2 / 3$ & 37 & 1 & 91.12 & 1.10 & 0.05 & 0.01 to 0.41 & $<0.001$ \\
\hline Total & 5 & 0 & 16.16 & 0.00 & 0.00 & _ & 0.090 \\
\hline
\end{tabular}

Table 2. Risk of hemorrhage following embolization in CAVM patients associated with several factors adjusted by multivariate Cox proportional hazards modeling.

\begin{tabular}{lccc}
\hline Variable & RR & $90 \% \mathrm{Cl}$ & $\mathrm{p}$ \\
\hline $\begin{array}{l}\text { Obliteration rate } \\
\quad \leq 1 / 3^{*}\end{array}$ & 1.00 & - & - \\
$\quad>1 / 3$ to $\leq 2 / 3$ & 0.36 & 0.15 to 0.87 & 0.055 \\
$\quad>2 / 3$ & 0.08 & 0.01 to 0.46 & 0.019 \\
$\begin{array}{l}\text { Topography } \\
\quad \text { Convexity }\end{array}$ & 1.00 & & \\
$\quad$ Deep & 2.72 & 1.10 to 6.77 & - \\
$\quad$ Infratentorial & 1.04 & 0.17 to 6.31 & 0.971 \\
$\begin{array}{l}\text { Presentation with } \\
\text { hemorrhage }\end{array}$ & & & \\
$\quad$ Yes & & & \\
$\quad$ No* & 5.00 & 1.31 to 19.00 & 0.047 \\
Presence of aneurysm & 1.00 & - & - \\
$\quad$ & & & \\
$\quad$ Yes & 0.94 & 0.37 to 2.41 & 0.921 \\
$\quad$ No* & - & - & - \\
\hline *Reference category & & &
\end{tabular}

it is exactly in small lesions that embolization has the highest rates of cure ${ }^{8,22}$.

Luessenhop ${ }^{16}$ observed that partial embolization may reduce the risk of hemorrhage by reducing intranidal pressure. However, the reports found in the literature so far are inconclusive concerning the protective role of partial embolization ${ }^{7,12,16,18,23}$, since any residue of malformed vessels has the potential to cause future bleeding, no matter what percentage of the lesion was obliterated ${ }^{15,18,22,23}$. Partial embolization has also been thought to increase the risk of CAVM rupture, even in patients without a previous hemorrhagic event ${ }^{8,10}$.

In the present cohort, the $5 \%$ yearly rate of bleeding recurrence was not significantly different from the $4 \%$ found by Ondra et al. ${ }^{6}$ in a 24 -year follow-up study of untreated CAVMs. The $1 \%$ mortality rate in our series was also similar to the rates reported by other authors for the natural history of $\mathrm{CAVMs}^{7}$. In addition, we observed that seizures were indeed a factor of protection against hemorrhage, and that the factors that were most significantly associated with subsequent hemorrhage were presentation with hemorrhage and low obliteration rate. The association between deep topography and hemorrhage was still present on multivariate analysis, although the power of the association was reduced.

Presentation with hemorrhage is generally accepted to be a strong predictor of bleeding recurrence in untreated $\mathrm{CAVMs}^{1,3,4,22}$. Some authors, however, 
have not observed this association ${ }^{18}$. On the other hand, presentation with seizures has been thought to be a factor of protection against bleeding ${ }^{1,14}$. In our series, out of 39 patients with seizures, only two had subsequent hemorrhage. In fact, careful analysis of angiographic studies for these cases showed evidence of accidental occlusion of drainage veins during NBCA embolization without immediate clinical effect. Therefore, in agreement with the literature, our results support the notion that nonhemorrhagic patients presenting with seizures are protected against later bleeding. Since the only two cases of hemorrhage in this group probably resulted from accidental occlusion of draining veins, we believe that partial embolization does not have any negative influence on the protective role of seizures.

Concerning obliteration rate, the multivariate analysis clearly shows that lesions with less than $2 / 3$ obliteration had proportionally higher rebleeding rates. Gobin did not observe this association in partially embolized patients who later underwent radiosurgery, but this might be explained by the fact that in that study a multivariate technique was not used for data analysis ${ }^{22}$. Our patients with less than $1 / 3$ obliteration bled even more often than expected had the lesion been untreated. Szikora ${ }^{24}$ also observed that patients with a low degree of obliteration had significantly higher hemorrhage rates than those expected for untreated lesions. For obliteration rates higher than $2 / 3$, we observed a rebleeding rate that was significantly lower than that expected in untreated lesions. None of the cAVMs with full angiographic occlusion hemorrhaged during follow-up, which is in agreement with other reports ${ }^{25}$. The higher bleeding rate in patients with a low degree of obliteration may be explained by intranidal hemodynamic changes with increased blood flow to regions prone to rupture. According to Pellettieri, partial obliteration may expose an occult compartment of the lesion that is not adapted to hyperflow and may consequently rupture ${ }^{23}$.

Findings concerning the topography of CAVM indicate that deep lesions are usually associated with presentation with hemorrhage, having a more aggressive clinical course and a tendency towards recurring hemorrhages (recurrence rate may reach $30 \%)^{2,20}$. After adjustment for several relevant factors, the association between deep lesion topography and occurrence of subsequent hemorrhage was confirmed (when compared to other locations), although the risk was reduced. This may be explained by a higher perfusion pressure, short arterial pedicles and venous drainage in deep lesions ${ }^{10,26}$.
Associated aneurysms, especially intranidal, are also considered a factor of increased risk for hemorrhage in untreated $\mathrm{CAVMs}^{2,12,27,28}$. The occlusion of aneurysms has been thought to confer relative protection ${ }^{2,12,29}$. but this was not what we observed in the present study, in which patients presented hemorrhage even after aneurysm occlusion. However, after controlling the effects of presentation with hemorrhage (Cox regression model), the relative risk associated with aneurysms practically disappeared. This suggests that in patients with CAVM, hemorrhage at presentation has a more important role in the occurrence of subsequent hemorrhage than the presence of an intranidal aneurysm. Thus, it seems that occlusion of intranidal aneurysms in patients presenting with hemorrhage does not have an impact on subsequent bleeding. This may be a result of factors associated with rupture, which have not yet been completely explained. Also, intranidal aneurysms may be the consequence, and not the cause, of hemorrhage at presentation. Other authors have already followed a similar line of reasoning ${ }^{2,29}$. We also agree with Redekop et al. ${ }^{28}$ and Stein, apud Turjman et al. ${ }^{27}$ in that the angiographic diagnosis of intranidal aneurysm is subjective and operator-dependent. Therefore, we again highlight the role of presentation with hemorrhage as the factor of highest relevance in the occurrence of subsequent hemorrhagic events.

In summary, the present results show that the relative risk of hemorrhage increases with CAVM obliteration rates below $1 / 3$. With obliteration rates between $1 / 3$ and $2 / 3$, the relative risk of hemorrhage is similar to that observed with the natural history of the disease; obliteration rates above 2/3 offer limited protection against hemorrhage, since the relative risk decreases in relation to the natural history. Full protection is only attained with $100 \%$ obliteration. In addition, occlusion of intranidal aneurysms in patients presenting with hemorrhage does not significantly affect the occurrence of subsequent bleeding, and presentation with hemorrhage seems to be the factor of highest relevance in predicting the occurrence of subsequent hemorrhagic events. Studying the present cohort, in which patients underwent NBCA embolization as the main treatment for CAVM, offered a unique opportunity for the study of outcomes with this therapeutic modality. Continued follow-up of this cohort may help explain the role of the main factors associated with the occurrence hemorrhagic events following embolization. 


\section{REFERENCES}

1. Crawford PM, West CR, Chadwick DW, Shaw MDM. Arteriovenous malformations of the brain: natural history in unoperated patients. J Neurol Neurosurg Psychiatry. 1986;49:1-10.

2. Marks MP, Lane B, Steinberg GK, Chang PJ. Hemorrhage in intracerebral arteriovenous malformations: angiographic determinants. Radiology. 1990;176:807-813.

3. Mast H, Young WL, Koennecke HC, et al. Risk of spontaneous haemorrhage after diagnosis of cerebral arteriovenous malformations. Lancet 1997;350:1065-1068.

4. Hartmann A, Mast H, Mohr JP, et al. Morbidity of intracranial hemorrhage in patients with cerebral arteriovenous malformations. Stroke 1998;29:931-934

5. Graf CJ, Perret GE, Torner JC. Bleeding from cerebral arteriovenous malformations as part of their natural history. J Neurosurg. 1983;58:331-337.

6. Ondra SL, Troupp H, George ED, Schwab K. The natural history of symptomatic arteriovenous malformations of the brain: a 24-year follow-up assessment. J Neurosurg. 1990;73:387-391.

7. Viñuela F, Dion J, Lylyk P, Duckwiler G. Update on interventional neuroradiology. Neuroimaging Clin N Am. 1992;2:279-289.

8. Wikholm G. Role of transarterial embolization in the management of cerebral arteriovenous malformations. Acta Radiologica 1996;37 (Suppl.):S3-S25.

9. Al-Yamany M, Terbrugge KG, Willinsky R, Montanera W, Tymianski, Wallace MC. Palliative embolisation of brain arteriovenous malformations with progressive neurological deficit. Interv Neuroradiol 2000;6:177-183.

10. Spetzler RF, Hargraves RW, McCormick PW, Zabranski JM, Flom RA, Zimmerman RS. Relationship of perfusion pressure and size to risk of hemorrhage from arteriovenous malformations. J Neurosurg. 1992; 76:918-923.

11. Kader A, Young WL, Pile-Spellman J, et al. The influence of hemodynamic and anatomic factors on hemorrhage from cerebral arteriovenous malformations. Neurosurgery 1994;34:801-808.

12. Lasjaunias P, Piske R, TerBrugge $K$, Willinsky R. Cerebral arteriovenous malformations (C.AVM) and associated arterial aneurysms (AA). Acta Neurochir (Wien) 1988;91:29-36.

13. Mansmann U, Meisel J, Brock M, Rodesch G, Alvarez H, Lasjaunias P. Factors associated with intracranial hemorrhage in cases of cerebral arteriovenous malformation. Neurosurgery. 2000;46:272-281.

14. Forster DMC, Steiner L, Hakanson S. Arterionevenous malformations of the brain: a long-term clinical study. J Neurosurg 1972;37:562-570.

15. Guo WY, Karlsson B, Ericson K, Lindqvist M. Even the smallest remnant of an AVM constitutes a risk of further bleeding: case report. Acta Neurochir (Wien) 1993;121:212-215.
16. Luessenhop AJ, Mujica PH. Embolization of segments of the circle of Willis and adjacent branches for management of certain inoperable cerebral arteriovenous malformations. J Neurosurg. 1981;54:573-582.

17. Marks MP, Lane B, Steinberg GK, Sniper GJ. Intranidal aneurysms in cerebral arteriovenous malformations: evaluation and endovascular treatment. Radiology 1992;183:355-360.

18. Lundqvist C, Wikholm G, Svendsen. Embolization of cerebral arteriovenous malformations: Part II. Clinical aspects on complications and late outcome. Neurosurgery 1996;39:460-469.

19. Luessenhop AJ, Presper JH. Surgical embolization of cerebral arteriovenous malformations through internal carotid and vertebral arteries. J Neurosurg. 1975;42:443-451.

20. Lawton MT, Hamilton MG, Spetzler RF. Multimodality treatment of deep arteriovenous malformations: thalamus, basal ganglia, and brain stem. Neurosurgery 1995;37:29-36.

21. Spetzler RF, Martin NA. A proposed grading system for arteriovenous malformations. J Neurosurg 1986;65:476-483.

22. Gobin YP, Laurent A, Merienne L, et al. Treatment of brain arteriovenous malformations by embolization and radiosurgery. J Neurosurg 1996;85:19-28.

23. Pellettieri L, Svendsen P, Wikholm G, Carlsson CA. Hidden compartments in AVMs-A new concept. Acta Radiol 1997;38:2-7.

24. Szikora I, Barath K, Vadja J, Czirják S, Futó J, Nyáry I. Bleeding frequency following embolization of brain AVMs. Neuroradiology 1999; 41(Suppl):S45.

25. Wikholm G, Lundqvist C, Svendsen. Transarterial embolization of cerebral arteriovenous malformations. Improvement with experience. Am J Neuroradiol 1995;16:1811-1817.

26. Batjer H, Samson D. Arteriovenous malformations of the posterior fossa: clinical presentation, diagnostic evaluation, and surgical treatment. J Neurosurg 1986;64:849-856.

27. Turjman F, Massoud TF, Viñuela F, Sayre JW, Guglielmi G, Duckwiler G. Correlation of the angioarchitectural features of cerebral arteriovenous with clinical presentation of hemorrhage. Neurosurgery. 1995;37:856-862.

28. Redekop G, TerBrugge K, Montanera W, Willinsky R. Arterial aneurysms associated with cerebral arteriovenous malformations: classification, incidence, and risk of hemorrhage. J Neurosurg 1998;89:539-546.

29. Monaco RG, Rodesh G, Alvarez H, lizuka Y, Hui F, Lasjaunias P. Pseudoaneurysms within ruptured intracranial arteriovenous malformations: diagnosis and early endovascular management. Am J Neuroradiol 1993;14:315-321. 